\title{
Carbodiphosphorane-Catalyzed Hydroboration of Ketones and Imines
}

\author{
Cara R. Aversa-Fleener, ${ }^{a}$ Daniel K. Chang, ${ }^{a}$ Allegra L. Liberman-Martina*
}

We report the use of a cyclic carbodiphosphorane catalyst for ketone and imine hydroboration reactions. To our knowledge, this represents the first use of a carbodiphosphorane as an organocatalyst. The carbodiphospohorane shows superior catalytic activity compared to other neutral carbon nucleophiles tested.

Lewis bases have emerged as a powerful class of catalysts for sustainable organic transformations. ${ }^{1}$ Within the context of Lewis base catalysis, there has been significant recent interest in the use of neutral carbon nucleophiles as organocatalysts. Most prominently, $\mathrm{N}$-heterocyclic carbenes (NHCs) are established catalysts for a range of organic transformations. ${ }^{2}$ Other carbon nucleophiles have more recently appeared as organocatalysts, including $\mathrm{N}$-heterocyclic olefins, ${ }^{3}$ carbodicarbenes, ${ }^{4}$ and carbonyl-stabilized phosphorus ylides. ${ }^{5}$

Carbodiphosphoranes (CDPs) constitute an unusual class of molecules featuring a two-coordinate carbon center that is formally zerovalent and possesses two lone pairs (Figure 1). ${ }^{6} \mathrm{As}$ a result, the central carbon of a CDP is exceptionally electron rich. CDPs are of interest as ligands for transition metal and main group complexes, ${ }^{7}$ as they are more strongly donating than NHC ligands based on Tolman electronic parameters. ${ }^{8}$ Despite their rich coordination chemistry, to our knowledge, there are no previous reports using carbodiphosphoranes as organocatalysts. Herein, we disclose the use of the cyclic CDP $\mathbf{1}^{9}$ as a catalyst for the efficient hydroboration of ketones and imines.

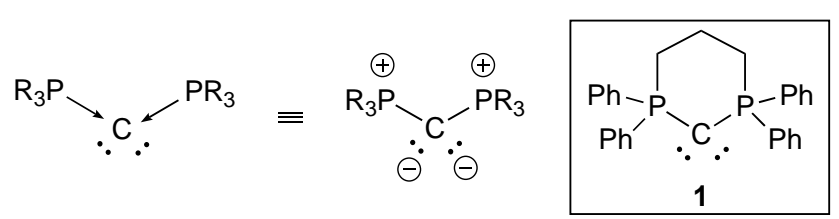

Figure 1. Two carbodiphosphorane (CDP) representations and the structure of cyclic CDP catalyst 1.
Ketone reduction is a widely used route to prepare alcohols. ${ }^{10}$ To complement hydrogenation methods, ketone hydroboration takes advantage of borane reagents, which can be used under mild reaction conditions and without the need for high-pressure apparatus. There have been significant advances developing main group and first-row transition metal catalysts for ketone hydroboration, ${ }^{11}$ with nucleophilic motifs appearing often as activators or catalysts. ${ }^{12}$

We have compared acetophenone hydroboration catalyzed by a range of neutral carbon nucleophiles as an initial proof-ofconcept for carbodiphosphorane catalytic activity. Reactions were performed using 1.1 equiv of pinacolborane (HBPin) and 5 mol\% catalyst loading in benzene- $d_{6}$ solvent for $1 \mathrm{~h}$ at $25{ }^{\circ} \mathrm{C}$ (Table 1). The $N$-heterocyclic carbene $\operatorname{IPr}(\operatorname{IPr}=1,3$-bis $(2,6-$ diisopropylphenyl)imidazol-2-ylidene) and its $\mathrm{N}$-heterocyclic olefin analog $\mathrm{IPrCH}_{2}$ have been previously reported by Rivard and coworkers to catalyze ketone and aldehyde hydroboration reactions. ${ }^{3 c}$ Under the reaction conditions tested, both IPr and $\mathrm{IPrCH}_{2}$ showed low conversion of acetophenone (3a) to its corresponding boronate ester (4a) after $1 \mathrm{~h}$ (Table 1 , entries 1 and $2 ; 17 \%$ and $33 \%$, respectively). The cumulated ylide $\mathrm{Ph}_{3} \mathrm{PCCO}$ showed limited catalytic activity (entry 3; $8 \%$ conversion), while the nitrile- and carbonyl-stabilized phosphorus ylides $\mathrm{Ph}_{3} \mathrm{PCHCN}$ (entry 4) and $\mathrm{Ph}_{3} \mathrm{PCHC}(\mathrm{O}) \mathrm{CH}_{3}$ (entry 5) were catalytically inactive.

High catalytic activity was observed using cyclic CDP 1 (entries 6 and 7), with 95\% acetophenone conversion achieved after $15 \mathrm{~min}$ using $1 \mathrm{~mol} \%$ catalyst loading. Interestingly, the unstabilized phosphorus ylide $\mathrm{Ph}_{3} \mathrm{PCH}_{2} 2$ was also highly active for acetophenone hydroboration (entries 8 and 9). The catalytic activity of $\mathbf{2}$ was unexpected, given the stoichiometric reactivity of phosphorus ylides with ketones in Wittig olefination reactions. ${ }^{13}$

\footnotetext{
a. Chemistry and Biochemistry Program, Schmid College of Science and Technology, Chapman University, One University Drive, Orange, CA 92866, USA Email: libermanmartin@chapman.edu

Electronic Supplementary Information (ESI) available including experimental procedures and spectroscopic data. DOI: 10.1039/x0xx00000x
} 
Table 1. Lewis basic catalyst comparison for acetophenone hydroboration. ${ }^{a}$

\begin{tabular}{|c|c|c|c|c|}
\hline & $\begin{array}{r}+\mathrm{HBF} \\
(1.1 \mathrm{e}\end{array}$ & $\frac{\text { catalys }}{25^{\circ} \mathrm{C}}$ & & $\underbrace{\mathrm{CH}_{3}}_{4 a} \stackrel{\mathrm{O}}{-\mathrm{BPin}}^{\mathrm{H}}$ \\
\hline Entry & Catalyst & $\begin{array}{c}\text { Catalyst } \\
\text { Loading } \\
\text { (mol\%) }\end{array}$ & $\begin{array}{l}\text { Time } \\
\text { (min) }\end{array}$ & $\begin{array}{c}\text { Conversion } \\
(\%)^{b}\end{array}$ \\
\hline 1 & $\mathrm{IPr}$ & 5 & 60 & $17 \%$ \\
\hline 2 & $\mathrm{IPrCH} 2$ & 5 & 60 & $33 \%$ \\
\hline 3 & $\mathrm{Ph}_{3} \mathrm{PCCO}$ & 5 & 60 & $8 \%$ \\
\hline 4 & $\mathrm{Ph}_{3} \mathrm{PCHCN}$ & 5 & 60 & $0 \%$ \\
\hline 5 & $\mathrm{Ph}_{3} \mathrm{PCHC}(\mathrm{O}) \mathrm{CH}_{3}$ & 5 & 60 & $0 \%$ \\
\hline 6 & cyclic CDP (1) & 5 & 60 & $99 \%$ \\
\hline 7 & cyclic CDP (1) & 1 & 15 & $95 \%$ \\
\hline 8 & $\mathrm{Ph}_{3} \mathrm{PCH}_{2}(2)$ & 5 & 60 & $99 \%$ \\
\hline 9 & $\mathrm{Ph}_{3} \mathrm{PCH}_{2}(2)$ & 1 & 15 & $90 \%$ \\
\hline
\end{tabular}

${ }^{a}$ Reaction conditions: acetophenone $(0.25 \mathrm{mmol}), \mathrm{HBP}$ in $(0.27$ $\mathrm{mmol})$, and catalyst $(0.013$ or $0.0025 \mathrm{mmol})$ in benzene- $d_{6}(0.50$ $\mathrm{mL}$ ) at $25^{\circ} \mathrm{C} .{ }^{b}$ Determined by ${ }^{1} \mathrm{H}$ NMR spectroscopy.

Scheme 1. Ketone scope for hydroboration reactions. ${ }^{a}$

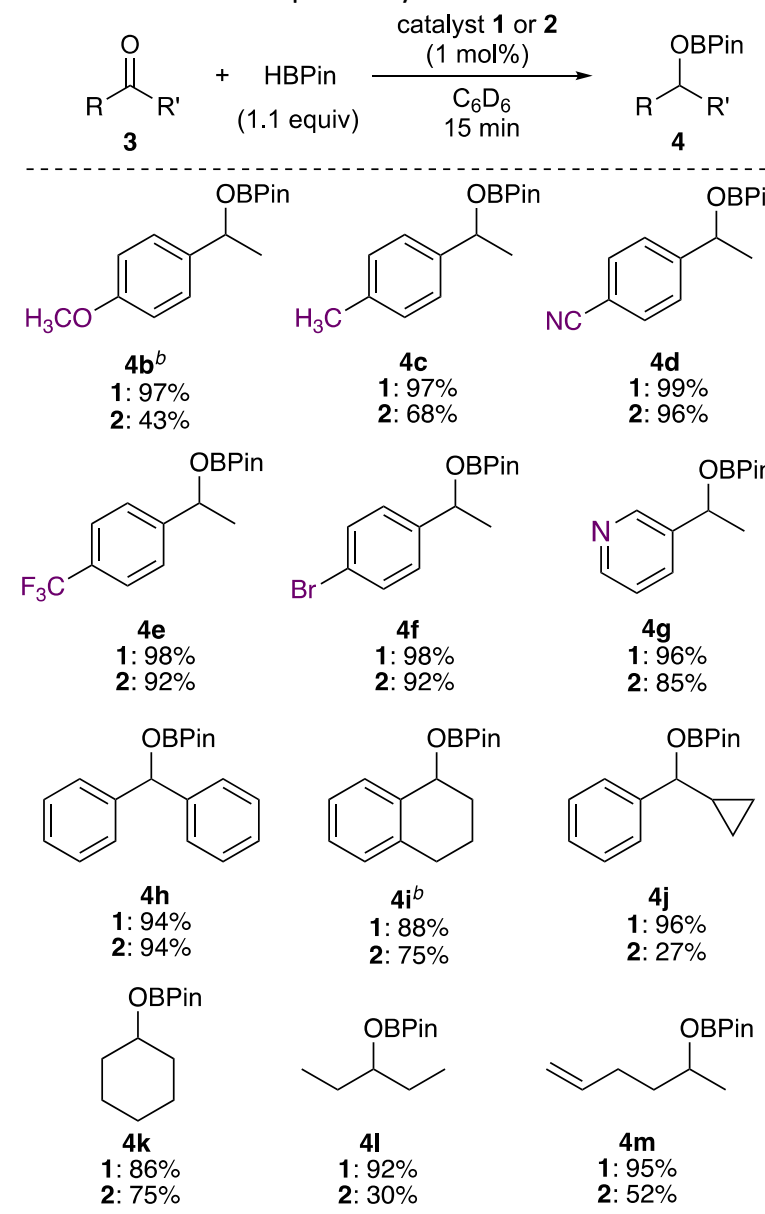

a Reaction conditions: ketone $(0.25 \mathrm{mmol}), \mathrm{HBPin}(0.27 \mathrm{mmol})$, and catalyst $(0.0025 \mathrm{mmol})$ in benzene- $d_{6}(0.50 \mathrm{~mL})$ at $25^{\circ} \mathrm{C}$ for $15 \mathrm{~min}$. Yields are based on ${ }^{1} \mathrm{H}$ NMR integration relative to a hexamethylbenzene internal standard. ${ }^{b} 30 \mathrm{~min}$.
Conversion of a variety of ketones $(\mathbf{3 b}-\mathbf{3 m})$ to their corresponding pinacol boronate esters $(\mathbf{4 b}-\mathbf{4 m})$ in the presence of $1 \mathrm{~mol} \%$ of catalyst 1 or $\mathbf{2}$ was investigated (Scheme 1). Most hydroboration reactions reached near completion within 15 minutes using catalyst 1 . Acetophenone derivatives featuring electron-donating (3b and $\mathbf{3 c}$ ) or electron-withdrawing (3d-3f) substituents were tolerated. The electron-rich 4'methoxyacetophenone (3b) underwent slower hydroboration than the electron-deficient acetophenone derivatives tested, requiring 30 minutes to achieve $97 \%$ yield using CDP catalyst 1 or $43 \%$ yield using phosphorus ylide catalyst 2. Rapid hydroboration of benzophenone (3h), a non-enolizable substrate was observed. Cyclopropylphenylketone (3j) was converted to its corresponding boronate ester product (4j) without the formation of ring-opened product, suggesting that a ketyl radical intermediate is not formed in the reaction mechanism. ${ }^{14}$ Alkyl-substituted ketones (3k-3m) also underwent efficient hydroboration using catalyst $\mathbf{1}$, though diminished activity towards these substrates was observed using catalyst 2. Chemoselective ketone hydroboration was observed in the presence of nitrile, pyridine, or alkene functional groups (substrates $\mathbf{3 d}, \mathbf{3 g}$, and $\mathbf{3 m}$ ).

We next explored reduction of imine substrates by catalysts $\mathbf{1}$ and 2. Imine hydroboration is a convenient method to prepare amine products, which are important in pharmaceutical, agrochemical, and materials chemistry applications. ${ }^{15}$ Hydroboration of $\mathrm{N}$-benzylideneaniline (5a) was attempted using a range of potential Lewis basic catalysts ( 5 mol\% loading), and catalytic activities were compared after $1 \mathrm{~h}$ at $25^{\circ} \mathrm{C}$ (Table 2). IPr, IPrCH 2 , and resonance-stabilized phosphorus ylides were essentially inactive for $\mathrm{N}$-benzylideneaniline hydroboration (entries 1-5). Phosphorus ylide $\mathbf{2}$ showed low activity for imine hydroboration (entry $6,22 \%$ conversion), while the CDP catalyst 1 showed high catalytic activity for conversion of $\mathbf{5 a}$ to the corresponding borylated amine product $6 a$ (entries 7 and 8 ).

Table 2. Lewis basic catalyst comparison for $\mathrm{N}$ benzylideneaniline hydroboration. ${ }^{a}$

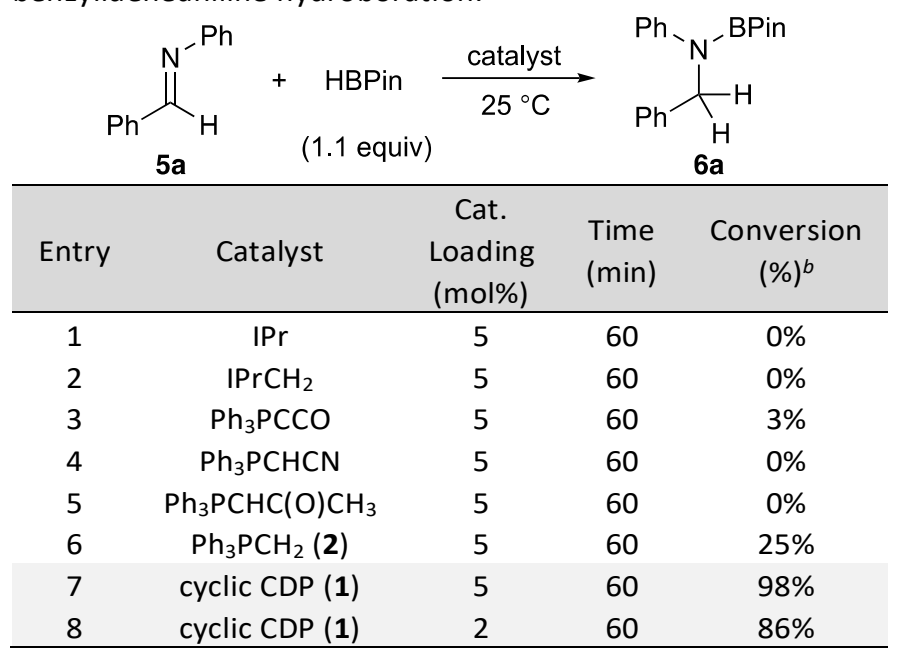

a Reaction conditions: $N$-benzylideneaniline $(0.25 \mathrm{mmol}), \mathrm{HBPin}$ $(0.27 \mathrm{mmol})$, and catalyst $(0.013$ or $0.0050 \mathrm{mmol})$ in benzene- $d_{6}$ $(0.50 \mathrm{~mL})$ at $25^{\circ} \mathrm{C} .{ }^{b}$ Determined by ${ }^{1} \mathrm{H}$ NMR spectroscopy. 
Hydroboration experiments using 2 mol\% of catalyst 1 or 2 were performed for a series of imine substrates $(\mathbf{5 b} \mathbf{- 5 g})$ with varied substituents on the imine nitrogen atom (Scheme 4). Phosphorus ylide $\mathbf{2}$ was an inefficient hydroboration catalyst for most imines tested (the $\mathrm{N}$-sulfonyl substrate $\mathbf{5 e}$ was an exception). Using CDP catalyst 1, increasing the size of the $N$ alkyl substituent (substrates $\mathbf{5 b} \mathbf{- 5} \mathbf{d}$ ) led to greatly diminished hydroboration activity. Imine substrates featuring $\mathrm{N}$-sulfonyl (5e) and $\mathrm{N}$-Boc (5f) functional groups were tolerated by catalyst 1. Cyclic ketimine $\mathbf{5 g}$ also underwent hydroboration to form product $\mathbf{6 g}$ in $97 \%$ or $75 \%$ yield using catalyst 1 or $\mathbf{2}$ respectively.

Scheme 4. Imine scope for hydroboration reactions. ${ }^{a}$

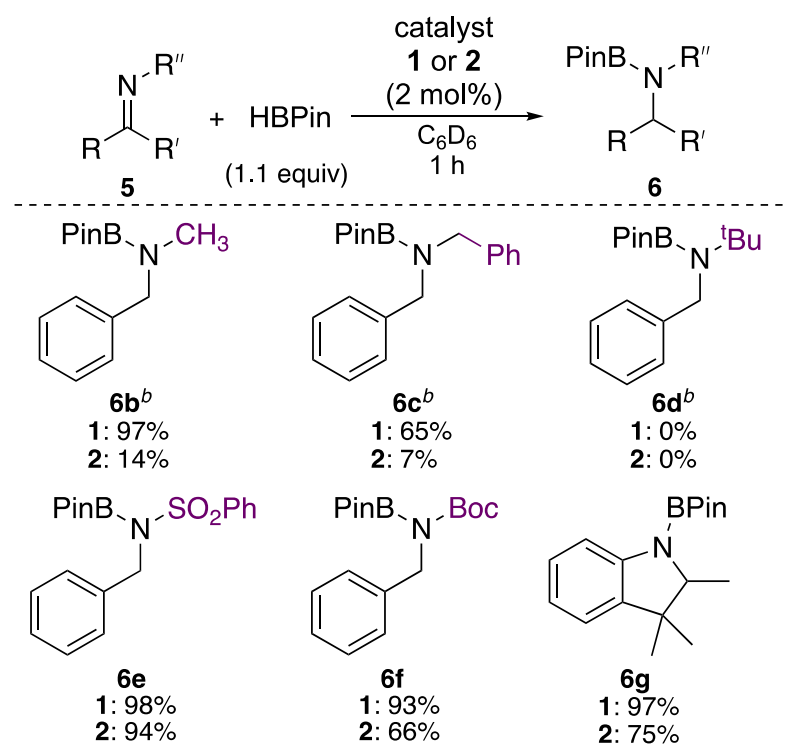

${ }^{a}$ Reaction conditions: imine $(0.25 \mathrm{mmol}), \mathrm{HBP}$ in $(0.27 \mathrm{mmol})$, and catalyst $(0.0050 \mathrm{mmol})$ in benzene- $d_{6}(0.50 \mathrm{~mL})$ at $25^{\circ} \mathrm{C}$ for $1 \mathrm{~h}$. Yields are based on ${ }^{1} \mathrm{H}$ NMR integration relative to a hexamethylbenzene internal standard. ${ }^{b} 1.5$ equiv of HBPin.

Stoichiometric experiments were performed between catalysts $\mathbf{1}$ or $\mathbf{2}$ and hydroboration substrates to gain insight into potential reaction mechanisms. Treatment of phosphorus ylide 2 with 1 equiv of HBPin caused an upfield shift in the ${ }^{11} \mathrm{~B}$ NMR signal and a diminished $J_{\mathrm{BH}}$ coupling constant $\left(\delta=29.5 \mathrm{ppm}, J_{\mathrm{BH}}\right.$ $=174 \mathrm{~Hz}$ for free pinacolborane vs $\delta=15.0 \mathrm{ppm}, J_{\mathrm{BH}}=140 \mathrm{~Hz}$ upon treatment with 1 equiv of 2). These spectroscopic changes are consistent with partial, reversible coordination of $\mathbf{2}$ to pinacolborane. ${ }^{16}$ The reaction of CDP 1 with pinacolborane was more complex. Upon combination of equimolar 1 and HBPin, an upfield shifted signal with reduced ${ }^{1} \mathrm{H}-{ }^{11} \mathrm{~B}$ coupling was observed by ${ }^{11} \mathrm{~B}$ NMR spectroscopy $\left(\delta=5.4 \mathrm{ppm}, J_{\mathrm{BH}}=109 \mathrm{~Hz}\right)$; however, a mixture of products was observed by ${ }^{31} \mathrm{P}$ NMR spectroscopy within minutes at $25{ }^{\circ} \mathrm{C}$. Under catalytic conditions using CDP 1, trace amounts of $\mathrm{BH}_{3}$ can be observed by ${ }^{11} \mathrm{~B}$ NMR spectroscopy, suggesting that 1 can mediate the formation of $\mathrm{BH}_{3}$ from pinacolborane; however, previous work by Thomas and coworkers has shown that Lewis base-mediated ketone hydroboration does not proceed by hidden $\mathrm{BH}_{3}$ catalysis. ${ }^{12 a}$
The stoichiometric reactivity of catalysts $\mathbf{1}$ and $\mathbf{2}$ with imine and ketone substrates was also examined. No reaction was observed upon treatment of either compound $\mathbf{1}$ or $\mathbf{2}$ with 1 equiv of $\mathrm{N}$-benzylidenemethylamine (5a) at $25^{\circ} \mathrm{C}$. Combining ylide 2 with 1 equiv of benzophenone ( $3 \mathrm{~h}$ ) resulted in Wittig olefination to form 1,1-diphenylethylene and triphenylphosphine oxide within 5 minutes at $25{ }^{\circ} \mathrm{C}$, with no intermediates observed by ${ }^{1} \mathrm{H}$ or ${ }^{31} \mathrm{P}$ NMR spectroscopy. The triphenylphosphine oxide product does not catalyze acetophenone hydroboration.

CDP 1 reacts with 1 equiv of benzophenone at $25^{\circ} \mathrm{C}$ to form the ring-opened ylide 7 (Scheme 5). Compound 7 does not catalyze acetophenone hydroboration. The ${ }^{1} \mathrm{H}$-decoupled ${ }^{31} \mathrm{P}$ NMR spectrum of 7 exhibits two doublets $(\delta=28.4$ and 20.0 ppm, $J_{\mathrm{PP}}=21.3 \mathrm{~Hz}$ ), which is similar to NMR data reported for $\mathrm{Ph}_{3} \mathrm{PCHP}(\mathrm{O}) \mathrm{Ph}_{2} .{ }^{17}$ The ylidic carbon of $\mathbf{7}$ appears as a doublet of doublets $\left(J_{\mathrm{CP}}=120.9,104 \mathrm{~Hz}\right)$ at $\delta=6.9 \mathrm{ppm}$ in ${ }^{13} \mathrm{C}$ NMR spectra. A plausible mechanism leading to the formation of $\mathbf{7}$ involves tautomerization of carbodiphosphorane 1 to an unsymmetrical double ylide form, ${ }^{18}$ followed by Wittig olefination.

Scheme 5. Reaction of $\mathbf{1}$ with benzophenone.

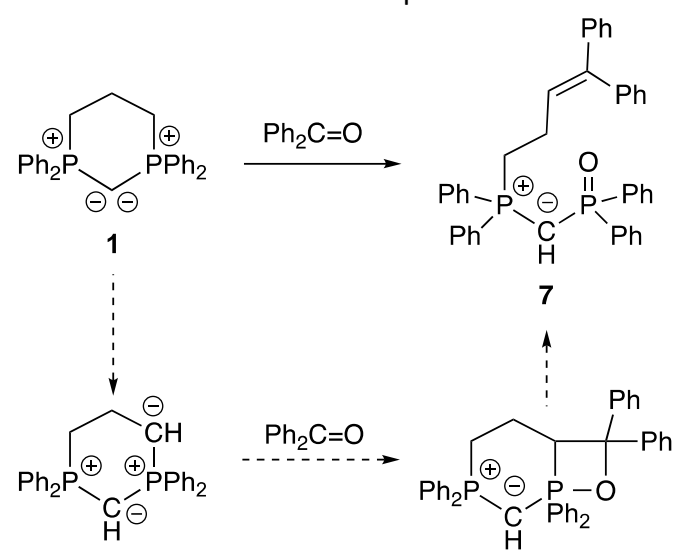

Based on the stoichiometric reactivity observed, two mechanistic pathways for ketone hydroboration are plausible (Scheme 6). ${ }^{3 c}$ Carbodiphosphorane 1 may coordinate to pinacolborane (Scheme 6, top), rendering the borane more hydridic. Hydroboration could then occur by hydride transfer to the ketone and $\mathrm{B}-\mathrm{O}$ bond formation, followed by carbodiphosphorane dissociation. Alternatively, catalyst 1 could first coordinate to the ketone substrate (Scheme 6, bottom). Subsequent borane binding to oxygen followed by hydride transfer could furnish the pinacol boronate ester product. Analogous possible mechanisms can be envisioned for imine hydroboration. Although the carbodiphosphorane form of $\mathbf{1}$ is drawn in Scheme 6 , the stoichiometric reactivity with benzophenone suggests that a tautomerized form of $\mathbf{1}$ may be accessible and could be the active catalyst. In future work, we hope to thoroughly investigate the hydroboration mechanisms of carbodiphosphorane catalysts.

In conclusion, cyclic carbodiphosphorane $\mathbf{1}$ is an efficient catalyst for ketone and imine hydroboration at $25^{\circ} \mathrm{C}$. To our knowledge, this is the first reported organocatalytic activity of a carbodiphosphorane. For comparison, we also surveyed the 
catalytic activity of phosphorus ylide 2. Compared to 2, carbodiphosphorane $\mathbf{1}$ affords higher yields of ketone hydroboration products and shows greatly enhanced activity in imine hydroboration reactions. Future work in our group will expand the use of carbodiphosphoranes and phosphorus ylides as Lewis basic organocatalysts.

Scheme 6. Plausible ketone hydroboration mechanisms.

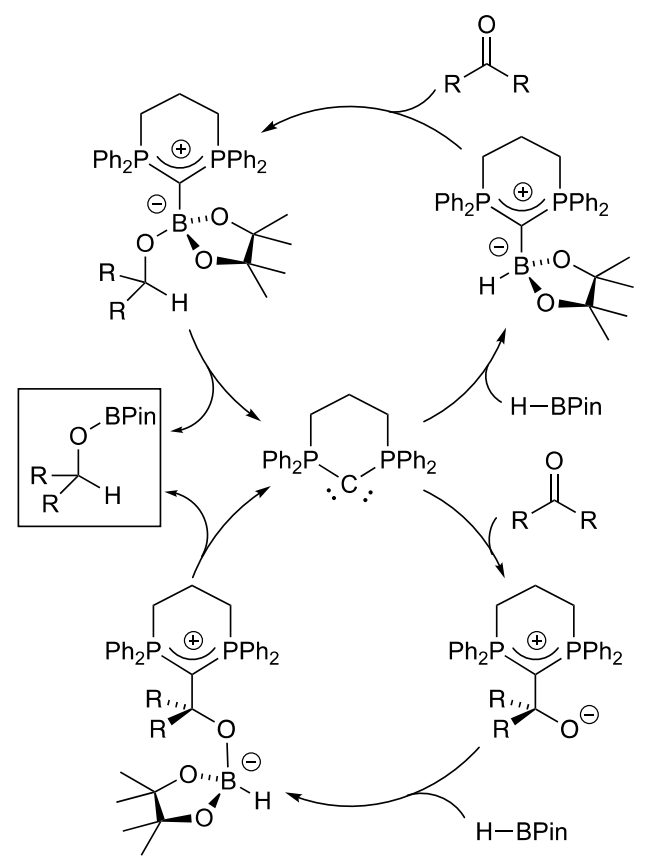

This work was supported by the American Chemical Society Petroleum Research Fund (62239-UNI1) and Chapman University, including the Faculty Opportunity Fund and the Center for Undergraduate Excellence. Profs. Miles W. Johnson and O. Maduka Ogba are thanked for helpful discussions.

\section{Notes and references}

1 (a) J. Seayad and B. List, Org. Biomol. Chem., 2005, 3, 719; (b) S. E. Denmark and G. L. Beutner, Angew. Chem. Int. Ed., 2008, 47, 1560-1638; (c) M. North, Sustainable catalysis: catalysis without metals or other endangered elements, The Royal Society of Chemistry, Cambridge, UK, 2016.

2 A. T. Biju, N-Heterocyclic Carbenes in Organocatalysis, Wiley-VCH Verlag GmbH \& Co. KGaA, Weinheim, Germany, 2018.

3 (a) M. Blümel, J.-M. Noy, D. Enders, M. H. Stenzel and T. V. Nguyen, Org. Lett., 2016, 18, 2208-2211; (b) U. Kaya, U. P. N. Tran, D. Enders, J. Ho and T. V. Nguyen, Org. Lett., 2017, 19, 1398-1401; (c) C. Hering-Junghans, I. C. Watson, M. J. Ferguson, R. McDonald and E. Rivard, Dalton Trans., 2017, 46, 7150-7153; (d) S. Naumann, Chem. Commun., 2019, 55, 11658-11670; (e) Z. Zhang, S. Huang, L. Huang, X. Xu, H. Zhao and X. Yan, J. Org. Chem., 2020, 85, 12036-12043.

4 W.-C. Chen, J.-S. Shen, T. Jurca, C.-J. Peng, Y.-H. Lin, Y.-P. Wang, W.-C. Shih, G. P. A. Yap and T.-G. Ong, Angew. Chem. Int. Ed., 2015, 54, 15207-15212.

5 (a) H. Zhou, G.-X. Wang, W.-Z. Zhang and X.-B. Lu, ACS Catal., 2015, 5, 6773-6779; (b) Y. Toda, T. Sakamoto, Y. Komiyama, A. Kikuchi and H. Suga, ACS Catal., 2017, 7, 6150-6154; (c) M. A.
Ansari, D. Yadav, S. Soni and M. S. Singh, Org. Biomol. Chem., 2019, 17, 9151-9162; (d) W.-B. Wu, X.-P. Zeng and J. Zhou, J. Org. Chem., 2020, 85, 14342-14350.

6 R. Tonner, F. Öxler, B. Neumüller, W. Petz and G. Frenking, Angew. Chem. Int. Ed., 2006, 45, 8038-8042.

7 (a) S. Khan, G. Gopakumar, W. Thiel and M. Alcarazo, Angew. Chem. Int. Ed., 2013, 52, 5644-5647; (b) C. Pranckevicius, D. A. Iovan and D. W. Stephan, Dalton Trans., 2016, 45, 16820-16825; (c) L. Maser, J. Herritsch and R. Langer, Dalton Trans., 2018, 47, 10544-10552; (d) M. Klein, X. Xie, O. Burghaus and J. Sundermeyer, Organometallics, 2019, 38, 3768-3777; (e) J. E. Münzer, N.-J. H. Kneusels, B. Weinert, B. Neumüller and I. Kuzu, Dalton Trans., 2019, 48, 11076-11085; (f) P. J. Quinlivan, D. G. Shlian, E. Amemiya and G. Parkin, Dalton Trans., 2019, 48, 91399151; (g) A. Kroll, H. Steinert, L. T. Scharf, T. Scherpf, B. Mallick and V. H. Gessner, Chem. Commun., 2020, 56, 8051-8054; (h) N.J. H. Kneusels, J. E. Münzer, K. Flosdorf, D. Jiang, B. Neumüller, L. Zhao, A. Eichhöfer, G. Frenking and I. Kuzu, Dalton Trans., 2020, 49, 2537-2546; (i) M. Klein and J. Sundermeyer, Organometallics, 2021, 40, 2090-2099.

8 W. Petz, F. Weller, J. Uddin and G. Frenking, Organometallics, 1999, 18, 619-626.

9 H. Schmidbaur, T. Costa, B. Milewski-Mahrla and U. Schubert, Angew. Chem. Int. Ed. 1980, 19, 555-556.

10 M. L. Shegavi and S. K. Bose, Catal. Sci. Technol., 2019, 9, 33073336.

11 (a) C. C. Chong and R. Kinjo, ACS Catal., 2015, 5, 3238-3259; (b) K. Revunova and G. I. Nikonov, Dalton Trans., 2015, 44, 840-866; (c) M. S. Hill, D. J. Liptrot and C. Weetman, Chem. Soc. Rev., 2016, 45, 972-988; (d) S. R. Tamang and M. Findlater, Molecules, 2019, 24, 3194; (e) K. Kuciński and G. Hreczycho, Green Chem., 2020, 22, 5210-5224.

12 (a) A. D. Bage, T. A. Hunt and S. P. Thomas, Org. Lett., 2020, 22, 4107-4112; (b) I. P. Query, P. A. Squier, E. M. Larson, N. A. Isley and T. B. Clark, J. Org. Chem. 2011, 76, 6452-6456; (c) Y. Wu, C. Shan, J. Ying, J. Su, J. Zhu, L. L. Liu and Y. Zhao, Green Chem. 2017, 19, 4169-4175; (d) Z. Zhu, X. Wu, X. Xu, Z. Wu, M. Xue, Y. Yao, Q. Shen and X. Bao, J. Org. Chem. 2018, 83, 10677-10683; (e) D. H. Ma, A. K. Jaladi, J. H. Lee, T. S. Kim, W. K. Shin, H. Hwang and D. K. An, ACS Omega, 2019, 4, 15893-15903.

13 B. E. Maryanoff and A. B. Reitz, Chem. Rev., 1989, 89, 863-927.

14 (a) L. Li, E. Liu, J. Cheng and G. Zhang, Dalton Trans., 2018, 47, 9579-9584; (b) S. Vijjamarri, T. M. O’Denius, B. Yao, A. Kubátová and G. Du, Organometallics, 2020, 39, 3375-3383.

15 D. J. C. Constable, P. J. Dunn, J. D. Hayler, G. R. Humphrey, J. L. Leazer, Jr., R. J. Linderman, K. Lorenz, J. Manley, B. A. Pearlman, A. Wells, A. Zaks and T. Y. Zhang, Green Chem., 2007, 9, 411-420.

16 (a) B. Wrackmeyer, in Annual Reports on NMR Spectroscopy, Elsevier, 1988, vol. 20, pp. 61-203; (b) H. Nöth and B. Wrackmeyer, in Nuclear Magnetic Resonance Spectroscopy of Boron Compounds, eds. H. Nöth and B. Wrackmeyer, Springer Berlin Heidelberg, Berlin, Heidelberg, 1978, pp. 102-108; (c) C. Pettinari, in Encyclopedia of Analytical Science, Elsevier, 2005, pp. 286-303.

17 W. Petz, F. Öxler, K. Aicher and B. Neumüller, Z. Anorg. Allg. Chem., 2010, 636, 1751-1759.

18 (a) C. Krüger, J. C. Sekutowski, R. Goddard, H. J. Füller, O. Gasser and H. Schmidbaur, Isr. J. Chem., 1976, 15, 149-152; (b) H. Schmidbaur, O. Gasser, C. Krüger and J. C. Sekutowski, Chem. Ber., 1977, 110, 3517-3527. 